\title{
EDITORIAL
}

\section{An Uptake of COVID-19 Vaccine: Hesitancy and the Strategies to Overcome}

\author{
Subhash C Parija ${ }^{1}$, Saurabh R Shrivastava ${ }^{2}$ \\ SBV Journal of Basic, Clinical and Applied Health Science (2021): 10.5005/jp-journals-10082-03127
}

\section{INTRODUCTION}

Coronavirus disease-2019 (COVID-19) pandemic continues to affect the masses even after almost 2 years since it was detected first in 2019, and during this time, millions of people have lost their lives due to infection-related complications. As a matter of fact, a cumulative total of more than 246 million cases and 4.9 million deaths have been attributed to the novel viral infection, as of November 3, 2021. ${ }^{1}$ There is no doubt that gradually things have started to come back to normal in some parts of the world, and this has been predominantly because of the implementation of prevention strategies (viz. use of face masks, covering face and mouth while coughing or sneezing, maintaining social distancing, practicing hand hygiene, and restricting unnecessary visits to crowded places) that have played an important role. ${ }^{2}$

\section{COVID-19 VACCINES}

At the same time, the introduction of effective COVID-19 vaccines has also been instrumental in saving the lives of millions, by not only reducing the risk of acquisition of infection but also by ensuring that immunized people do not eventually land up into severe forms of the infection. ${ }^{2}$ A number of vaccines, such as AstraZeneca/Oxford vaccine, Johnson and Johnson, Moderna, Pfizer/BionTech, Sinopharm, and Sinovac, have been recommended for administration in different parts of the world based on their safety and efficacy. The need of the hour is that regardless of your COVID-19 status (whether you had the infection in the past or not), we (viz. people older than 18 years of age) should get vaccinated at our turn without any delay. ${ }^{2}$

\section{Vaccination among Children and Adolescents}

Though there have been uncertainties about vaccinating children and adolescents, the clinical trials are still going on and soon we will have conclusive evidence about vaccinating these population groups as well. However, till then, all children should continue to have the already approved vaccines for other infectious diseases, as per the national immunization schedule. ${ }^{1,2}$ We have to understand that even after being vaccinated, we should continue to practice the preventive strategies, as no vaccine gives $100 \%$ protection, and thereby minimize the risk of acquisition of infection and subsequent financial load and overburdening of the healthcare delivery system. ${ }^{2,3}$
${ }^{1}$ Vice-Chancellor, Sri Balaji Vidyapeeth (Deemed to be University), Puducherry, India

${ }^{2}$ Department of Community Medicine, Shri Sathya Sai Medical College and Research Institute (A Unit of Sri Balaji Vidyapeeth Deemed to be University), Kancheepuram, Tamil Nadu, India

Corresponding Author: Saurabh R Shrivastava, Department of Community Medicine, Shri Sathya Sai Medical College and Research Institute (A Unit of Sri Balaji Vidyapeeth Deemed to be University), Kancheepuram, Tamil Nadu, India, e-mail: drshrishri2008@gmail.com

How to cite this article: Parija SC, Shrivastava SR. An Uptake of COVID-19 Vaccine: Hesitancy and the Strategies to Overcome. J Basic Clin Appl Health Sci 2021;4(4):79-80.

Source of support: Nil

Conflict of interest: None

\section{Vaccine Hesitancy: Strategies to Overcome}

Even though vaccines have demonstrated immense potential, we have seen that there are many sections of the general population who are against the vaccine and thus are reluctant to get the vaccine. This calls for the need to enhance the level of trust about the vaccine among the masses and make people really understand the actual benefits that the vaccine provides and the varied consequences that can emerge if we acquire the infection. ${ }^{3}$ In order to accomplish this, we have to adopt specific strategies, including

- Targeting social media: It is a fact that a wide range of false or incomplete information has been circulating in social media, both about the infection and also about the vaccine, which has played an important role in people being reluctant to take the vaccine. If we aim to counter these, we have to come ahead with a better media campaign, which has to be run by the reputed leaders from different walks of life and thereby encourage people to get vaccinated at the earliest. ${ }^{2,3}$

- Accepting the views of people: There is no harm in accepting the fact that currently, we lack adequate information about the long-term safety of the available vaccines. However, the kind of information that needs to be passed on to the masses is the disastrous consequences of COVID-19 infection and the impact that the disease has demonstrated since its introduction. The idea is that people have to understand and accept that what

(c) The Author(s). 2021 Open Access This article is distributed under the terms of the Creative Commons Attribution 4.0 International License (https://creativecommons org/licenses/by-nc/4.0/), which permits unrestricted use, distribution, and non-commercial reproduction in any medium, provided you give appropriate credit to the original author(s) and the source, provide a link to the Creative Commons license, and indicate if changes were made. The Creative Commons Public Domain Dedication waiver (http://creativecommons.org/publicdomain/zero/1.0/) applies to the data made available in this article, unless otherwise stated. 
these vaccines are protecting them from so that eventually we can maintain a balance between the risk and benefits attributed to the vaccination. Furthermore, we have to also make people realize that the primary goal of vaccination is to ensure the safety of people and reduce the rates of mortality among them. Once we are able to achieve it, we can aim to interrupt the chain of transmission effectively and thus eventually hope that no longer people have to wear face masks. ${ }^{2,3}$

\section{Conclusion}

To conclude, there is no point in criticizing people that why they are refusing vaccines, especially when the disease can prove to be fatal. The need of the hour is to accept all these views and strengthen our media campaign and make people also understand that the overall benefits of getting vaccinated clearly outweigh the risks that people are anticipating, and thus the right decision will be to get ourselves vaccinated at our turn.

\section{References}

1. World Health Organization. Weekly operational update on COVID-19November 3, 2021. 2021. Available from: https://www.who.int/ publications/m/item/weekly-operational-update-on-covid-19-3november-2021 [Last accessed on November 5, 2021].

2. World Health Organization. COVID-19 advice for the public: getting vaccinated. 2021. Available from: https://www.who.int/emergencies/ diseases/novel-coronavirus-2019/covid-19-vaccines/advice [Last accessed on November 5, 2021].

3. Laine C, Cotton D, Moyer DV. COVID-19 vaccine: promoting vaccine acceptance. Ann Intern Med 2021;174(2):252-253. DOI: 10.7326/ M20-8008. 